\title{
The Philosophy of Intransitive Preference
}

\author{
Paul Anand
}

The Economic Journal, Vol. 103, No. 417. (Mar., 1993), pp. 337-346.

Stable URL:

http://links.jstor.org/sici?sici=0013-0133\%28199303\%29103\%3A417\%3C337\%3ATPOIP\%3E2.0.CO\%3B2-X

The Economic Journal is currently published by Royal Economic Society.

Your use of the JSTOR archive indicates your acceptance of JSTOR's Terms and Conditions of Use, available at

http://www.jstor.org/about/terms.html. JSTOR's Terms and Conditions of Use provides, in part, that unless you have obtained prior permission, you may not download an entire issue of a journal or multiple copies of articles, and you may use content in the JSTOR archive only for your personal, non-commercial use.

Please contact the publisher regarding any further use of this work. Publisher contact information may be obtained at http://www.jstor.org/journals/res.html.

Each copy of any part of a JSTOR transmission must contain the same copyright notice that appears on the screen or printed page of such transmission.

The JSTOR Archive is a trusted digital repository providing for long-term preservation and access to leading academic journals and scholarly literature from around the world. The Archive is supported by libraries, scholarly societies, publishers, and foundations. It is an initiative of JSTOR, a not-for-profit organization with a mission to help the scholarly community take advantage of advances in technology. For more information regarding JSTOR, please contact support@ jstor.org. 
The Economic Journal, ro3 (March), 337-346. (C) Royal Economic Society 1993. Published by Blackwell Publishers, 108 Cowley Road, Oxford OX 4 IJF, UK and 238 Main Street, Cambridge, MA 02 I $_{4}^{2}$, USA.

\section{THE PHILOSOPHY OF INTRANSITIVE PREFERENGE*}

\section{Paul Anand}

Sometimes seen as the touchstone of formal theories of rational choice, transitive preferences have become the centre of a decision theoretic controversy that is of import to both economic theorists and philosophers. Empirically, there is mounting evidence based on observations of choice behaviour under controlled laboratory conditions that agents do not have preferences consistent with even the weakest forms of transitivity (see, for instance, Grether and Plott (1979), Korhonen et al. (1990) and Bradbury and Ross (1990)). Whilst it is understandable that researchers might be sceptical about the significance of individual empirical studies, it is also true that the frequent replication of these findings has had a noticeable impact on the development of decision theory in the I980s. From a technical viewpoint there are a number of mathematical representation and uniqueness theorems (generalisations of utility theory) which dispense with the transitivity assumption (e.g. Morrison (1962), Tversky (1969), Bell (1982), Fishburn (1982), and Loomes and Sugden (1982)).

Despite the importance of rationality in economic analysis, work dealing with the normative interpretation of, and warrants for, axioms like transitivity was not, until the I 980 , widely discussed. The change is illustrated by two major surveys of the normative justification of the independence assumption ${ }^{1}$ given in McClennen (1989) and Machina (1991), whilst a further survey covering completeness, transitivity and independence can be found in Anand ( 1987 ). A review of examples in which rational choice appears to run counter to transitivity is given in Bar-Hillel and Margalit (1988). Furthermore, new species of rational choice theory are beginning to appear - see for instance Sen (I985) or Anand (I99I). ${ }^{2}$ Furthermore, references to these literatures in works such as Kreps (1990) micro text indicate that genuine interest in such issues is no longer confined to debates in a range of philosophy and specialist decision theory journals.

For all that, there would seem to be no single place in the general economics literature where normative arguments relating to transitivity can be found.

\footnotetext{
* This paper is based on presentations given to the Royal Economics Society conference and a Recent Advances in the Philosophy of Science symposium held in Amsterdam, I9-2 I August I99 I. I am grateful to Bill Harper, Wlodzimierz Rabinowicz, an anonymous referee and participants of both events for their comments as well as to the Royal Economic Society which funded part of the work through a Post-doctoral Fellowship.

1 In this case, independence refers to the assumption that utility is linear in the probability argument.

2 The paper deals with the conceptual issues in a way that is standard in philosophy. We focus here not on the logical consequences of particular assumptions but on the justification for making a particular assumption. The task requires arguments which are not of mathematical interest though they are of consequence to formulators of applied mathematical theories. Whilst these kinds of arguments are the norm in philosophy some economic theorists believe they are arbitrary. I know of no arguments that will convince either side that the other is correct and it would, therefore, be futile to try and justify the methodology that the paper (and the literature of which it is part) employs.
} 
This paper aims to fill that gap and focuses on the logic of arguments concerning an hermeneutic hypothesis, namely that transitivity is necessitated by the ideal of rational agency. Sections I, II and III deal with the principal arguments whilst section IV briefly mentions a number of remaining issues.

\section{INTRANSITIVITY AS INGONSISTENGY - THE LOGIGAL GASE}

There is a sense in which intransitive choices appear to be a profound form of error. Transitive preferences are just a matter of logic, and it is natural to suppose that their negation must be logically inconsistent. Any observed violations would be judged as irrational in much the same way that we take behaviour based on incorrect syllogistic inference ${ }^{3}$ so to be. The very title of Georg Von Wright's The Logic of Preference makes this association explicit as does Broome (199I) though one of the earliest explorations of this position, from which the following passage is taken, appears in Tullock (1964, p. 403):

The proof of intransitivity is a simple example of reductio ad absurdum. If the individual is alleged to prefer $A$ to $B, B$ to $C$, and $C$ to $A$, we can enquire which he would prefer from the collection of $A, B$, and $C$. Ex-hypothesi he must prefer one, say he prefers $A$ to $B$ or $C$. This however contradicts the statement that he prefers $C$ to $A$, and hence the alleged intransitivity must be false.

If the agent is assumed to prefer $B$ or $C$, then a similar sort of contradiction can be produced. But what really has been proved? (In the following discussion, we use lower case for choice objects and upper case for preference relations nothing of substance depends on whether preferences are strong or weak.) It seems we have a proof which says that a statement of choice from the feasible set $\{a, b, c\}$ contradicts a statement in the set of possible binary preference rankings $\{B a b, B b c, B a c\}$ where $B$ denotes binary preference. Strictly speaking any choice from the threesome would indicate something about ternary preferences (which will be denoted by the predicate $T^{4}$ ). They would, therefore ${ }^{5}$ belong to $\{T a b c, T a c b, T b c a, T b a c, T c a b, T c b a\}$, none of which is an element of $\{\neg B a b, \neg B b c, \neg B a c\}$, though one must be, if a contradiction is to be obtained.

The problem here is that the attempted proof confounds two- and threeplace predicates. In general these relations are different: ' $m$ divided by $n$ ' and 'Lucifer is the friend of Eve' are propositions involving binary relations whilst ' $r$ is the integral part of $m$ divided by $n$ ' and 'Lucifer is the mutual friend of Eve and Adam' both exemplify ternary relations. The binary and ternary relations are not unrelated but neither are they one and the same and this is true for all relations.

If it is tempting to use $>$ as a symbol and analogy for strict preference, then perhaps it is easy to think that preferences over options and the 'greater than' relation over real numbers share structural features. The value of predicate

${ }^{3}$ See, for instance, experimental work on syllogistic reasoning by Johnson-Laird and Wason (1970).

4 To be read as in the binary case: e.g. Tabc should be read ' $a$ is preferred to $b$ is preferred to $c$ '.

${ }^{5}$ Embedded in the 'therefore' is a completeness assumption: nothing hangs on this but assuming it makes what drives the argument more transparent. 
notation is in reminding us that the chaining of relations, which transitivity expresses, is a matter of choice, not a given. To pretend otherwise is to commit the fallacy of question begging. Nonetheless, it may be that a link between binary and ternary preferences can be constructed and that this link serves to demonstrate what is being presupposed. We now examine the plausibility of such a link.

A principle which would complete the proof is one known as contraction consistency. The idea is that if you have a preference between two choice objects, this should be unaffected if other items are removed from the choice set. Formally, we might state the assumption thus:

\section{$T a b c \Rightarrow B a b \wedge B b c \wedge B a c$.}

Contraction consistency lets one infer transitive binary preferences immediately. This leads to the not entirely obvious conclusion that the appeal of transitivity may hinge on our acceptance of the contraction constraint (see Anand (1982) and Sugden (1985)). The normative question has not been solved, it has merely been relocated: must rational agents order their preferences so they abide by contraction? A view which answers this in the negative depends on noting that members of the feasible set go to make up the context in which choice is exercised. Choices made from differing opportunity sets can have quite different meanings (gestalt) just as they might draw on very different forms of justification or explanation. To see this, and its force in undermining contraction, I offer the following problem. ${ }^{6}$

First suppose that you are being asked to say whether you think patients should normally be able to see their medical records and that your preference is a as follows:

\section{$\neg$ access to records $>$ access to records.}

If patients could see anything and everything that health workers wrote about them, clinicians might spend much of their time, and taxpayers' money, responding to requests for access to medical records instead of treating patients. A person who reasoned thus might have the preference in ( $\mathrm{I}$ ). Now suppose a third option 'access only to records electronically stored' is introduced. The voter's deliberations might well take a different tack. Perhaps access to electronically stored medical records would satisfy the demands of natural rights without impinging unduly on clinicians' time and so be preferred to the no 'access' option. On the other hand, it might be claimed that access to a subset of medical records introduces an incentive for health care workers to keep data they may not wish to reveal out of computerised information systems thus circumventing the aim of disclosure laws. Under the circumstances, it might be thought preferable to have access to all medical records, regardless of the form of storage. A person who thought so would have preferences of the following nature:

access to records $>$ access to computerised records $>\neg$ access to records.

6 The problem is loosely based on the comments of a Labour MP broadcast by the BBC radio programme Today in Parliament.

(C) Royal Economic Society I 993 
In case it needs to be made explicit, this is not an argument that the person aspiring to rationality must have the constellation of preferences implied by (I) and (2). All that is claimed is that, were a person to have such preferences, for reasons such as those outlined, it would hardly be fanciful to say they were intelligible and coherent. Indeed, one might say that the difficulty is in finding any grounds at all on which the conjunction of (I) and (2) could be deemed irrational. However, if contraction is not a principle of rational choice, then Tullock's attempted logical argument remains a non sequitur.

\section{INTRANSITIVITY AS INGONSISTENGY - THE SEMANTIC GASE}

There is a second, superficially weaker, but more intuitively appealing, view which suggests that transitivity is constitutionally embedded in the meaning of preference. An elegant expression of this argument can be found in - if it is not due to-Davidson (1980, p. 237):

The theory... is so powerful and simple, and so constitutive of concepts assumed by further satisfactory theory... that we must strain to fit our findings, or interpretations, to fit the theory. If length is not transitive, what does it mean to use a number of measure length at all? We could find or invent an answer, but unless or until we do, we must strive to interpret 'longer than' so that it comes out transitive. Similarly 'for preferred to'.

The core of the argument lies in the view of measure theory in general and in particular the properties of the relation 'is longer than'. Certainly, it would be difficult to imagine how something might have more than one numerical length. Even in Wonderland, Alice's different heights were sequential. If length is the sort of attribute which can be signified by a single number, and the comparative relation of 'is longer than' is a relation which can be modelled by the 'is greater than' relation (as normally defined over real numbers), then it seems inevitable that 'is longer than' will be transitive.

All this we can admit, and still ask what it has to do with preferences: 'similarly' with preference is Davidson's reply. The crux of the argument is not the embeddedness of transitivity in the relation 'is longer than', but the assertion of an analogy between preference and length, an analogy for which a warrant should be provided. In fact it could be said that Davidson's argument is a double analogy between relations (preference and length) and the way both come to have the property of being transitive. In both cases transitivity is alleged to be a property embedded in the meaning of the relation, and not, for example, a property either relation just happens, empirically, to have.

In general, the modern practice is to avoid, where we can, the use of analogies. For one thing, there is no decisive solution to the problem of how we should evaluate analogies such as the one Davidson draws. A possible evaluation procedure is to see if there are other analogies which might be drawn and either confirm, or otherwise, the claim being made. We might

(C) Royal Economic Society I 993 
suggest that the determination of a consumer's preference between two commodities, say, is more like the judgment of a competition in which players or teams compete in a pairwise fashion. However, we know that in competitions, a first-division team might beat one from a second division which in turn might defeat one a division below and yet the third-division team could turn out to be giant-killers and beat the first-division team. This is hardly a view which necessitates vast imaginative leaps either to invent or understand and indeed it is a line of reasoning that has occurred to a number of researchers. ${ }^{7}$ I do not wish to suggest that this is a more plausible metaphor than lengthmeasurement, merely that both are plausible and intelligible - this is all one needs to undercut the constitutional case as it stands.

\section{THE MONEY PUMP}

The money pump is a well-popularised reductio ad absurdum which purports to show that an intransitive agent can be made to give up all her wealth. Suppose an agent has an intransitive set of binary strict preferences as below:

$$
\begin{aligned}
& P a b \\
& P b c \\
& P c a .
\end{aligned}
$$

If the above preferences can be translated directly into behaviour then by (4) the agent is willing to trade in $c$ for $b$ and give up some strictly positive amount of wealth. By (3), the agent will trade $b$ and some strictly positive amount of wealth for $a$ but by (5), $a$ and yet more wealth would be given up for $c$. At that point, we know by the repeated application of $(4)$ that the agent is willing to part with $c$ and more wealth for the allure of $b$ and so on until the agent has been pumped dry of every sou. The agent is a dupe and only a Panglossian fool would regard the cycle of trades as being for the best, so the story goes.

If, however, the agent were not told at the start that the decision problem was one in which a sequence of opportunity sets was to be presented over time then we would not be forced to judge the undesirable series of actions as irrational. We could say they were the unsurprising consequences of having only partial information about future options. In addition, it might be noted that the temporal reading of transitivity implied by the money pump argument cannot preclude the possibility that tastes might change over time, and most would see that as a decision-maker's prerogative.

One, mathematically inspired, response to the above is to question timebound interpretations and defences of transitivity. Properly, we should think of transitivity as a constraint that only applies to preferences at a single point in time and it is this simultaneous interpretation from which the axiom derives its appeal. ${ }^{8}$ We have now two interpretations, one dynamic and one simultaneous, both of which must be addressed.

7 The point was first made to me by Paul Seabright. Sugden (1985) makes a similar point.

8 I am indebted to Frank Hahn for suggesting this line of reasoning. 
Let us examine the perhaps more appealing, simultaneous interpretation first. Useful as it is, the idea of a simultaneous interpretation is not entirely unproblematic. If it is taken to mean that the agent is confronted with three different feasible sets simultaneously why do we not count them as one decision problem? Perhaps one should read $P a b$ as the counterfactual proposition 'if you could choose between $a$ and $b$, you would choose $a$ ' and, in the context of the money pump argument, 'if you could choose between $a$ and $b$, you would swap $b$ and some strictly positive finite amount for $a^{\prime}$. (3) to (5) would then become:

$$
\begin{aligned}
& F=\{a, b\} \square \rightarrow \operatorname{swap} b \text { for } a \text { and yield } \epsilon \\
& F=\{b, c\} \square \rightarrow \operatorname{swap} c \text { for } b \text { and yield } \epsilon^{\prime} \\
& F=\{a, c\} \square \rightarrow \operatorname{swap} a \text { for } c \text { and yield } \epsilon^{\prime \prime},
\end{aligned}
$$

where $F$ is the feasible set, $\epsilon, \epsilon^{\prime}$, and $\epsilon^{\prime \prime}$ are strictly greater than zero and $\square \rightarrow$ is the counter-factual connective '... if it were the case that ... then the following would happen ...' '. The preferences in (6) to (8) say how a person would choose given a variety of possible opportunity sets and the preferences are not transitive. To see how pernicious this is, we must follow the consequences of every possibility. Suppose the actual opportunity set turns out to be $\{a, b\}$ : then even with some strictly positive transaction costs, the agent will trade $b$ for $a$. Nothing to complain about in that. Now suppose that the feasible set were $\{a, c\}$. In this case, the agent would give up $a$ for $c$ and be willing to pay some positive sum for the pleasure. Again there is nothing here on which to base a charge of irrationality and the same conclusion would be drawn if we considered what would happen were $b$ and $c$ feasible. Insofar as we can understand the constraint operating in a simultaneous sense, it seems that none of the possible outcomes has anything like the disastrous consequences that tellers of the money pump story claim.

Dynamic choice problems involve choice over time and in that context we tend to think the problem with intransitive preferences lies with consequences that befall the agent faced with a particular sequence of opportunity sets. It seems that if a person is confronted with the choice sequence $\{a, c\},\{b, c\}$, and $\{a, b\}$ where the feasible sets are offered at times $t, t+\mathrm{I}$ and $t+2$ respectively, then they can be taken from $a$ back to $a$ and will pay $\epsilon^{\prime \prime}+\epsilon^{\prime}+\epsilon$ for the privilege. Formally, the concern is that if we allow intransitive preferences, then a dynamic choice problem which is constructed by aggregating the antecedent conditions of the individual counterfactuals in (6) to (8) will prove to be the demise of any agent whose choices can be described by the aggregation of the consequents of those same counterfactuals.

As the song says, 'it ain't necessarily so'. Despite the similarities between conditionals and counterfactuals there are differences of which we are becoming increasingly aware from theories such as those due to Lewis (1986). Here lies a difference that matters. In propositional logic, if it is the case that $P \rightarrow X, Q \rightarrow Y$ and $R \rightarrow Z$ (here upper case letters denote propositions) then $P \wedge Q \wedge R \vdash X \wedge Y \wedge Z$. The slogan is: if you aggregate antecedents, you can construct the consequent by aggregating the consequents of component 
conditionals. To see that this is an aspect on which conditionals and counterfactuals differ, consider what might happen if, whilst attending a conference in a foreign country, you were to lose some money. Suppose in each of three variants of this possible calamity, one of the things you would do is to drown your sorrows in a bottle of the local beer. The counterfactuals relating to three forms of loss are summarised below:

$$
\text { lose cash } \square \rightarrow \text { have a beer }
$$

lose credit cards $\square \rightarrow$ have a beer

lose traveller's cheques $\square \rightarrow$ have a beer.

Whether cash is taken from your wallet, the credit cards drop from your jacket or your traveller's cheques are stolen from your hotel room, you think that you would have a beer. However, there is also a small, ghastly chance that you could be deprived of all three forms of liquidity simultaneously. From this it does not follow that you would have three beers (or even one) because it might be that you would have nothing with which to purchase such solace as a drink might provide. Aggregation of consequents from individual counterfactuals does not follow from aggregation of antecedents as it does with conditionals.

Here is another way of making the point. An experimenter asks a subject for preferences over three feasible sets and on finding they are intransitive points out to the subject the fact that these preferences expose the subject to the dangers of being money-pumped in sequential choices. The subject then asks the experimenter on what grounds preferences over specific opportunity sets are used to infer behaviour over the concatenation of these sets. The subject points out that if the experimenter had asked what choices would be made in the super game now proposed, his choices would be different. Moreover, he points out that given the intransitive preferences he has, it would be absurd to use them as the basis for a decision rule in the dynamic choice problem the experimenter was proposing. Their use would indeed be absurd, but who was it that was proposing the application?

\section{REMAINING PROBLEMS}

Many other arguments can be found in the literature but the following comments concern the more important of these. Two attempted defences, based on ideas of decidability and ratifiability, are inadequate for reasons similar to those discussed in the context of Tullock's logical argument. The decidability argument says that intransitive preferences yield no particular ranking of options. However, we saw that there is nothing in logic that requires $n$-ary preferences to be easily derivable from higher-order preferences. Strictly, decidability only requires that preferences relevant to the decision problem are well defined, so that if the choice is from three objects, only the ternary preference ranking needs to exist. Similarly with ratifiability. Suppose your preferences are $P a b, P b c$ and $P c a$ and that you have to choose from the set $\{a, b, c\}$. Whatever you do, it seems there will always be something better you 
could do, so no decision is ratifiable. However, anyone who claimed that they were satisfied with a particular choice could point out that only the ternary preferences were relevant.

It is worth asking whether there are situations in which it seems positively desirable to violate transitivity and I mention two examples that seem worthy of consideration. First image that you are at a friend's dinner party and your host is about to offer you some fruit. ${ }^{9}$ If you are proffered an orange or small apple, you would rather have the orange, and if the choice is between a large apple and an orange you decide you would rather have the large apple. As it happens your friend is out of oranges and emerges from the kitchen with two apples, one large and one small. How should you choose? Etiquette seems to suggest that one might take the small apple and I find it difficult to see why such a choice must be judged irrational. ${ }^{10}$ The second example arises in the context of a competitive game. This statistical 'paradox', which appears in Blyth (I972) and was independently formulated by Packard (I982), shows that choice over pairs of lotteries can be intransitive for agents who want to maximise the probability of winning. To see this, suppose there are three options, $\alpha, \beta$ and $\gamma$ with consequences depending on the outcome of six possible mutually exclusive states, $s$ I to $s 6$ (Table I). The game is played as follows.

Table I

\begin{tabular}{cccccccc}
\hline \hline & \multicolumn{8}{c}{ States } \\
\cline { 2 - 8 } & Options & $s 1$ & $s 2$ & $s 3$ & $s 4$ & $s 5$ & $s 6$ \\
\hline$\alpha$ & $\mathrm{I}$ & $\mathrm{I}$ & 4 & 4 & 4 & 4 \\
$\beta$ & 3 & 3 & 3 & 3 & 3 & 3 \\
& $\gamma$ & 5 & 5 & 2 & 2 & 2 & 2 \\
\hline \hline
\end{tabular}

Two possible dice are specified in advance by some third, neutral party. One player must choose a die leaving the alternative for the other player. Each throws their die and the winner is the person with the highest number. The dice are fair so the probability of any one state is $1 / 6$. Outcomes on each die are independent of those on the other. If a player wants to maximise the probability of winning, it is easy to show that the binary preferences must be: $P \alpha \beta P \beta \gamma$ and $P \gamma \alpha$.

Particularly in response to the second kind of example, it is sometimes suggested that the violations of transitivity can be removed by redefining the choice primitives. But then one wonders whether transitivity is a feature of behaviour or of language and in Anand (1990), it is shown formally that any 'intransitive' behaviour can be given a transitive description: conversely any

\footnotetext{
${ }^{9}$ I thank Bob Sugden for this example, though its original provenance is unknown. See also May (1954) for an empirical example.

${ }^{10}$ Note this does not require the existence of internal conflicts which can also rationalise intransitive preference, Kelsey ( 1986 ).
}

(C) Royal Economic Society I 993 
'transitive' behaviour can be given an intransitive description. Elsewhere (Anand, in press) I argue that this is not a problem that classical utility theory can easily solve. ${ }^{11}$

To conclude, the paper has touched on what I believe are the key issues concerning the normative justification for transitivity. Whilst philosophers are usually willing to take the arguments in isolation, many economists are more concerned about the impact on economic theory. As mathematical economists have developed versions of consumer theory and general equilibrium, the effects for practitioners are not nearly so devastating as might have been supposed. Indeed the philosophical arguments give normative support to the mathematical generalisations of expected utility that drop transitivity. However, my aim has been neither to attack nor defend mathematical practice in economics but merely to take the philosophical claims made for certain axioms at face value. Furthermore I do not even say that expected utility should never be used (it is of considerable pedagogic value), but I do believe we are in the midst of rethinking our ideas about rationality and the role it should play in economic theory, and that we must recognise the contributions that philosophy makes to this re-evaluation.

\section{Templeton College and University of Oxford}

\section{REFERENCES}

Anand, P. ( I982). 'How to be right without being rational.' Oxford Agrarian Studies, vol. I I, pp. I 58-72. Anand, P. (1987). 'Are the preferences really rational?' Theory and Decision, vol. 23, pp. I89-2 I4.

Anand, (I 99o). 'Interpreting axiomatic (decision) theory.' Annals of Operations Research, vol. 23, pp. 9I-I I I. Anand, P. (I99I). 'The nature of rational choice and The Foundations of Statistics.' Oxford Economic Papers, vol. 43 , pp. 199-2 16 .

Anand, P. (in press) The Foundations of Rational Choice Under Risk. Oxford: Oxford University Press.

Bar-Hillel, M. and Margalit, A. (I988). 'How vicious are cycles of intransitive choice.' Theory and Decision, vol. 24, pp. I I $9-45$.

Bell, D. ( I 982). 'Regret in decision making under uncertainty.' Operations Research, vol. 20, pp. 96I-8I.

Blyth, G. (1972). 'Some probability paradoxes in choice from among random alternatives.' Journal of the American Statistical Association, vol. 67, pp. 367-73.

Bradbury, H. and Ross, K. (I990). 'The effects of novelty and choice materials on the intransitivity of preferences of children and adults.' Annals of Operations Research, vol. 23, pp. I4 I-59.

Broome, J. (I99I). Weighing Goods. Oxford: Basil Blackwell.

Davidson, D. (1980). Essays on Actions and Events. Oxford: Glarendon Press.

Fishburn, P. (1982). 'Non-transitive measurable utility.' Journal of Mathematical Psychology, vol. 26, pp. $3 \mathrm{I}-67$.

Grether, D. M. and Plott, G. R. (1979). 'Economic theory of choice and the preference reversal phenomenon.' American Economic Review, vol. 69, pp. 623-38.

Hammond, P. (1988). 'Consequentialist foundations for expected utility.' Theory and Decision, vol. 25, pp. $25^{-78 .}$

Johnson-Laird, P. N. and Wason, P. G. (I970). 'Insight into a logical relation.' Quarterly Journal of Experimental Psychology, vol. 22, pp. 49-61.

Kelsey, D. (I 986). 'Utility and the individual.' Social Choice and Welfare, vol. 3, pp. 77-87.

Korhonen, P., Moskowitz, H. and Wallenius, J. ( I990). ' Changing behaviour in interactive multiple-criteria decision making.' Annals of Operations Research, vol. 23, pp. i6 $6 \mathrm{I}-79$.

Kreps, D. M. (1990). A Course in Microeconomic Theory. New York: Harvester Wheatsheaf.

Lewis, D. ( 1986$)$. Counterfactuals. Oxford: Basil Blackwell.

Loomes, G. and Sugden, R. (I982). 'Regret theory.' Economic Journal, vol. 92, pp. 805-24.

McGlennen, E. F. (I 989). 'Sure-thing doubts.' In (P. Gardenfors and N.-E. Sahlin eds.) Decision Probability and Utility. Cambridge: Cambridge University Press.

11 Though see Hammond ( 1988 ) for a different viewpoint.

(C) Royal Economic Society I 993 
Machina, M. (I99I). 'Dynamic consistency and non-expected utility.' In (M. Bacharach and S. Hurley eds.) Foundations of Decision Theory. Oxford: Basil Blackwell.

May, O. (1954). 'Intransitivity, utility and the aggregation of preference patterns.' Econometrica, vol. 20, pp. I-I3.

Morrison, H. W. (1962). 'Intransitivity of Paired Comparison Choices.' University of Michigan, PhD thesis.

Packard, D. J. (1982). 'Cyclical preference logic.' Theory and Decision, vol. I4, pp. 415-26.

Sen, A. K. (1985). 'Rationality and uncertainty.' Theory and Decision, vol. ı8, pp. Io9-27.

Sugden, R. (I985). 'Why be consistent?' Economica, vol. 52, pp. I67-84.

Tullock, G. (I964). 'The irrationality of intransitivity.' Oxford Economic Papers, vol. i6, pp. 40 I-6.

Tversky, A. (I969). 'Intransitivity of preferences.' Psychological Review, vol. 76, pp. 3I-48. 
http://www.jstor.org

\section{LINKED CITATIONS}

- Page 1 of 3 -

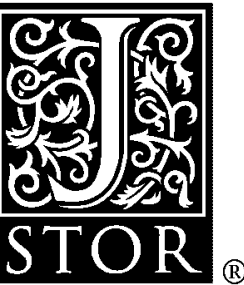

You have printed the following article:

The Philosophy of Intransitive Preference

Paul Anand

The Economic Journal, Vol. 103, No. 417. (Mar., 1993), pp. 337-346.

Stable URL:

http://links.jstor.org/sici?sici=0013-0133\%28199303\%29103\%3A417\%3C337\%3ATPOIP\%3E2.0.CO\%3B2-X

This article references the following linked citations. If you are trying to access articles from an off-campus location, you may be required to first logon via your library web site to access JSTOR. Please visit your library's website or contact a librarian to learn about options for remote access to JSTOR.

\section{[Footnotes]}

\footnotetext{
${ }^{7}$ Why be Consistent? A Critical Analysis of Consistency Requirements in Choice Theory Robert Sugden Economica, New Series, Vol. 52, No. 206. (May, 1985), pp. 167-183.

Stable URL:

http://links.jstor.org/sici?sici=0013-0427\%28198505\%292\%3A52\%3A206\%3C167\%3AWBCACA\%3E2.0.CO\%3B2-R
}

\footnotetext{
${ }^{9}$ A Set of Independent Necessary and Sufficient Conditions for Simple Majority Decision Kenneth O. May

Econometrica, Vol. 20, No. 4. (Oct., 1952), pp. 680-684.

Stable URL:

http://links.jstor.org/sici?sici=0012-9682\%28195210\%2920\%3A4\%3C680\%3AASOINA\%3E2.0.CO\%3B2-S
}

\section{References}

The Nature of Rational Choice and The Foundations of Statistics

Paul Anand

Oxford Economic Papers, New Series, Vol. 43, No. 2. (Apr., 1991), pp. 199-216.

Stable URL:

http://links.jstor.org/sici?sici=0030-7653\%28199104\%292\%3A43\%3A2\%3C199\%3ATNORCA\%3E2.0.CO\%3B2-W

NOTE: The reference numbering from the original has been maintained in this citation list. 
http://www.jstor.org

\title{
LINKED CITATIONS
}

- Page 2 of 3 -

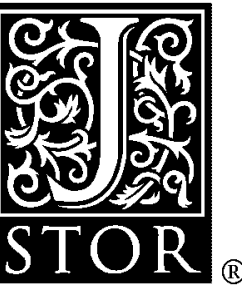

\author{
Regret in Decision Making under Uncertainty \\ David E. Bell \\ Operations Research, Vol. 30, No. 5. (Sep. - Oct., 1982), pp. 961-981. \\ Stable URL: \\ http://links.jstor.org/sici?sici=0030-364X\%28198209\%2F10\%2930\%3A5\%3C961\%3ARIDMUU\%3E2.0.CO\%3B2-A
}

Some Probability Paradoxes in Choice from Among Random Alternatives

Colin R. Blyth

Journal of the American Statistical Association, Vol. 67, No. 338. (Jun., 1972), pp. 366-373.

Stable URL:

http://links.jstor.org/sici?sici=0162-1459\%28197206\%2967\%3A338\%3C366\%3ASPPICF\%3E2.0.CO\%3B2-K

Economic Theory of Choice and the Preference Reversal Phenomenon

David M. Grether; Charles R. Plott

The American Economic Review, Vol. 69, No. 4. (Sep., 1979), pp. 623-638.

Stable URL:

http://links.jstor.org/sici?sici=0002-8282\%28197909\%2969\%3A4\%3C623\%3AETOCAT\%3E2.0.CO\%3B2-M

\section{Regret Theory: An Alternative Theory of Rational Choice Under Uncertainty}

Graham Loomes; Robert Sugden

The Economic Journal, Vol. 92, No. 368. (Dec., 1982), pp. 805-824.

Stable URL:

http://links.jstor.org/sici?sici=0013-0133\%28198212\%2992\%3A368\%3C805\%3ARTAATO\%3E2.0.CO\%3B2-1

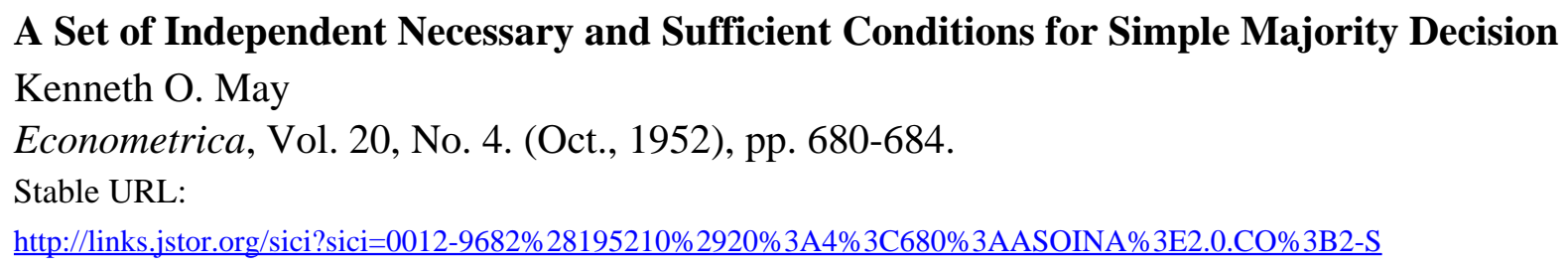

Why be Consistent? A Critical Analysis of Consistency Requirements in Choice Theory Robert Sugden

Economica, New Series, Vol. 52, No. 206. (May, 1985), pp. 167-183.

Stable URL:

http://links.jstor.org/sici?sici=0013-0427\%28198505\%292\%3A52\%3A206\%3C167\%3AWBCACA\%3E2.0.CO\%3B2-R

NOTE: The reference numbering from the original has been maintained in this citation list. 
http://www.jstor.org

\section{LINKED CITATIONS \\ - Page 3 of 3 -}

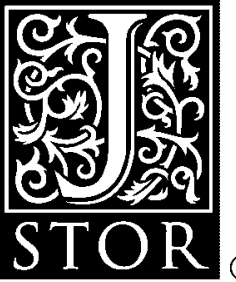

\section{The Irrationality of Intransitivity}

Gordon Tullock

Oxford Economic Papers, New Series, Vol. 16, No. 3. (Nov., 1964), pp. 401-406.

Stable URL:

http://links.jstor.org/sici?sici=0030-7653\%28196411\%292\%3A16\%3A3\%3C401\%3ATIOI\%3E2.0.CO\%3B2-7

NOTE: The reference numbering from the original has been maintained in this citation list. 